\title{
Communication in Relevance Theory
}

\author{
Nathalie Franken* \\ Université Libre de Bruxelles
}

\begin{abstract}
Sperber and Wilson (1995) ground their definition of communication on their criticism of Grice's intentional definition of non-natural meaning. In such a perspective, communication is considered as an act rather than as a process. Sperber and Wilson propose two definitions of this fundamental concept. In a first time, they argue that communication involves two specific intentions; afterwards, they equate it with ostension. This paper examines and criticizes their proposals, confronting them to ordinary intuition. Some crucial issues are discussed: the equivalence of Sperber and Wilson's two definitions, the nature of the evidence used in communication, the intentionality of communication, the content of the communicative intention, the notion of mutual manifestness, and the problem of infinite regress.
\end{abstract}

The analysis of communication is a central component of Relevance Theory. Sperber and Wilson's book (1986/1995) mentions communication in its subtitle and largely focuses on this topic. ${ }^{1}$ Indeed, Sperber and Wilson ${ }^{2}$ ground their own theory on a radical criticism of Grice's intentional conception of communication (see W\&S, 1979; S\&W, 1986/1995). In this paper, I would like to examine S\&W's views on communication in order to assess their internal coherence and to confront them to speakers' intuitions.

I will begin by distinguishing between two possible ways of considering communication, viz. as a process or as an act (which should not be confused with any speech act). I will try to characterize S\&W's approach to these two dimensions of speech activity. I will then discuss the two definitions of communication they propose and evaluate them empirically. 
My discussion will concern, among other things, the nature of the evidence used in communication, the intentions required, and the notion of mutual manifestness.

\section{Communication : act or process?}

Although they severely criticize Grice's attempts to account for communication as well as for interpretation processes, $S \& W$ consider that Grice's definition of non-natural meaning can be elaborated on in order to develop an inferential model of communication (see S\&W, 1995: 21).

Let us recall that, according to Grice, a communicator $\mathrm{C}$ non-naturally means (and thus communicates) something to an audience $\mathrm{A}$ by a stimulus $\mathrm{x}$ iff $\mathrm{C}$ has the following intentions:

(1) that $\mathrm{x}$ produces a response $\mathrm{r}$ to $\mathrm{A}$,

(2) that A recognizes (1) and

(3) that A's recognition of (1) at least partly motivates A's response $r$.

S\&W's criticism bears on two main points : the content of intentions (1)-(3) and the principle of cooperation, which, according to Grice, governs utterance production and interpretation. S\&W eventually propose to define communication by means of two intentions only, and to replace the principle of cooperation and the maxims derived from it by a single principle of relevance. Here I limit my discussion to the first issue, although the second one would also deserve some critical examination.

When examining Grice's definition, we notice that it mainly focuses on the communicator, who may be held responsible for an act of meaning or communication. In fact, $\mathrm{C}$ communicates if he produces a stimulus with the required intentions. So A's interpretation of C's act should not influence our qualification of it. In such a perspective, communication may be viewed as a particular kind of action, provided we admit that acting consists in intentionally modifying the environment. ${ }^{3}$ In my opinion, Relevance Theory adopts a similar approach: " ... an act of communication (in an appropriately restricted sense of the term) might be characterised as one that fulfils these Gricean intentions" (1995: 28). On the other hand, several alternative approaches reduce communication to a process which involves interaction. Those interactional models often rely on notions such as cooperation (see e.g. Allwood, 1976) or socialization (see e.g. Meijers, 1994) - assuming, then, some form of collective intentionality. Even if they informally define communication as a "process" (1995: 1), S\&W would probably reject such interactional models. Indeed, their purely individualistic framework cannot deal with the social dimensions of pragmatics. Moreover, in their technical definitions, they rather consider communication as an act.

Obviously, our daily concept of communication allows for both interpretations. But even if we adopt an interactional approach, we should concede that every communication process involves some actions such as, at least, C's production of a stimulus, A's 
interpretation of it, or A's reaction. Furthermore, the success of an act of communication does not depend on its recognition by the audience $A$. This condition only bears on the satisfaction of the act, which requires some "action" of A's. ${ }^{4}$ Thus, I feel entitled to limit my investigation to C's act of producing an utterance addressed to A, even though I must confess that considering such an act as part of a process may have further consequences for its characterization, and that my restrictive approach prevents me from giving a thorough account of communication.

In fact, communication is the only topic with respect to which Relevance Theory takes action into account. Indeed, according to S\&W, utterances convey thoughts and not actions, ${ }^{5}$ in particular, they claim that pragmatics need not integrate any theory of "speech acts". I won't discuss this issue any further here. ${ }^{6}$ Let me just recall that speech acts are not to be confused with the act of communication, despite the intricate relationships which hold between both categories.

\section{S\&W's conception of communication}

Before examining S\&W's own definition(s) of an act of communication, I would like to make two preliminary remarks. First, S\&W, like Grice, do not restrict their theory to verbal communication: language is only one of the means that one can rely on in order to communicate. Secondly, the thesis that "communication involves the publication and the recognition of intentions" (1995: 24) is a truism for S\&W, who assume that "from the psychological point of view, intentions are mental representations capable of being realised in the form of actions" (1995: 31).

According to Grice, C communicates only if he has intentions (1)-(3). However, communication involves something more than the simple fact of having some intentions: the communicator must produce a stimulus which makes his intentions manifest, i.e. he must make them accessible to the audience. In Grice's framework, the publicity of intentions is ensured both by positing intention (2), which requires that A should recognize intention (1), and by assuming that communicators are rational. Personally, I prefer to use, as do S\&W, a specific concept of manifestness. Since I will have to come back to this issue later, I quote here S\&W's definition of manifestness, as well as some related definitions that will prove relevant to the following discussion:

\footnotetext{
"A fact is manifest to an individual at a given time if and only if he is capable at that time of representing it mentally and accepting its representation as true or probably true. (...) To be manifest, then, is to be perceptible or inferable." (1995: 39).

"A cognitive environment of an individual is a set of facts that are manifest to him." (idem)

"Any shared cognitive environment in which it is manifest which people share it is what we call a mutual cognitive environment. In a mutual cognitive environment, for every manifest assumption, the fact that it is manifest to the
} 
people who share this environment is itself manifest. In other words, in a mutual manifest environment, every manifest assumption is what we call mutually manifest." (1995: 41-42).

As I have already pointed out, $S \& W$ criticize Grice's definition of communication on several points. But, in fact, in later papers, after taking in consideration some critical remarks and counter-examples, Grice himself modified his original definition. His critics had put into question the necessity of considering a perlocutionary intention (the first intention), ${ }^{7}$ the content of the third intention and the correlative requirement of indirect evidence, ${ }^{8}$ and the overtness of the communicative intention (in relation with the second intention). ${ }^{9}$ Grice (1989: 95-96) accepted, for instance, Strawson's objections about the second intention, viz. that his definition allows for some cases of deceit to be considered as communication, contrary to our intuitions. In order to ensure the overtness of communication, he proposed the following solution (1989: 95-100): since one is forced to introduce either a reflexive intention or an infinite regress in the intentions themselves, one should consider this reflexivity or infinite regress as an idealization, and consequently add to the three basic intentions the ceteris paribus clause that no deceitful intention operates at this juncture. S\&W reject the hypothesis of the infinite regress as being psychologically unplausible. According to them, it is unlikely that humans would even aim at such unachievable purposes. I will tackle this problem later in my discussion, while examining S\&W's putative way out, which rests on the notion of mutual manifestness. Roughly speaking, one could say that, in order to define communication, $S \& W$ modify intentions (1) and (2) drastically, and that they replace intention (3) by the requirement that $\mathrm{C}$ should give indirect evidence of his information. In fact, they formulate two definitions of communication. The first one relies on a description of the informative and communicative intentions at work; in the second one, communication is accounted for in terms of ostension.

\subsection{S\&W's first definition of communication}

S\&W want to distinguish communication from the simple transfer of information. If C only gives direct evidence for the information he wishes to convey, he does not communicate; to do so, he must provide A with indirect evidence for the information he wants to convey, and so with direct evidence of his intention to convey it, so that $A$ can infer what C's intentions are. For instance, $\mathrm{C}$ cannot communicate that he has a sore throat by simply letting hear his hoarse voice (see S\&W 1995: 22): "We have shown two different ways of conveying information. One way is to provide direct evidence for the information to be conveyed. This should not be regarded as a form of communication : any state of affairs provides direct evidence for a variety of assumptions without necessarily communicating those assumptions in any interesting sense. (...) Another way of conveying information is to provide direct evidence of one's intention to convey it. (...) This second method is clearly a form of communication" (1995: 23). Whether C, to communicate, relies or not on a code does not matter: "... coded communication is only used as a means of strengthening ostensive-inferential communication" (1995: 63). Unfortunately, S\&W do not specify the 
ways $C$ can use to make his intentions manifest, nor do they formulate any criterion which could distinguish neatly between both types of evidence.

Now, what are the intentions at work? There are two - an informative intention and a communicative intention: "A communicator produces a stimulus intending thereby (informative intention) to make manifest or more manifest to the audience a set of assumptions $\{\mathrm{I}\}$ " (1995: 58), "and intending moreover (communicative intention) to make it mutually manifest to audience and communicator that the communicator has this informative intention" (1995: 61). $\$ \& W$ also claim that "successful communication"10 only requires that the communicative intention be fulfilled. However, consider what they say in their final definition of ostensive-inferential communication : "the communicator produces a stimulus which makes it mutually manifest to communicator and audience that the communicator intends, by means of this stimulus, to make manifest or more manifest to the audience a set of assumptions $\{\mathbf{I}\}$ " (1995: 63). There is a least one reading of this definition which entails that the existence of a communicative intention is not a necessary condition for communication to take place. This accounts for the fact that $S \& W$ eventually claim that communication may be unintentional. I will question this claim later, when analyzing S\&W's alleged example of unintentional communication. Until then, I will consider that, for $S \& W, C$ communicates iff his communicative intention is fulfilled, that is iff the informative intention is made mutually manifest.

\subsection{S\&W's second definition of communication}

S\&W also try to reduce communication to ostension: "Can the term 'communication' be legitimately applied to all cases of ostension? Our answer is yes. (...) Inferential communication and ostension are one and the same process, but seen from two different points of view" (1995: 54). Ostension is a special kind of behaviour "which makes manifest an intention to make something manifest" (1995: 49) and its existence is beyond any doubt for S\&W. The intention involved obviously corresponds to the informative intention. However, it is less obvious that ostension also involves any communicative intention or simply any similar constraint. In fact, S\&W never establish the equivalence of both definitions, they only state it, illustrating their point of view with examples. They hold that the equation of communication with ostension follows from their rejection of the idea that communication "consists in providing evidence for what the communicator means" (1995: 54). According to them, such a characterization could not capture any clearcut class of phenomena. This point will be examined in detail in the next section.

\section{Indirect evidence}

S\&W's definitions of communication do not integrate any intentional requirement that could correspond to Grice's third intention. They rather stipulate that $\mathrm{C}$ has to give indirect evidence for the information he intends to convey, which means giving direct evidence of 
his intention to convey it. In fact, as noticed by Schiffer (1972: 56), Grice's third intention too encompasses such a constraint. S\&W justify their claim by pointing out that, while any state of affairs can make some assumptions manifest, nobody would say that "it communicates". However, such a process cannot be intentional either, so that nobody would ever confuse the two phenomena. In fact, whereas Grice wanted to eliminate any remnant of natural meaning from his analysis of communication in terms of non-natural meaning, S\&W think that there is no clear distinction between both varieties of meaning. They prefer to assume that the different cases of ostension rank on a continuum, which ranges from instances of showing to acts of saying. This seems to contradict their wish to distinguish clearly between transferring information and communicating. Personally, I think that the Gricean requirement of indirect evidence is unnecessary and even incorrect. In my opinion, $\mathrm{C}$ can communicate by giving direct evidence for his information as soon as he also displays evidence of his intention to communicate. This will happen, for instance, when it is clear enough that direct evidence is intentionally provided. I suppose that $S \& W$ could agree with me on this point.

To make his intentions manifest, $C$ has to rely on natural or conventional meaning. This requirement is never mentioned by Grice or $\mathrm{S} \& W$, but it seems unavoidable to me. As pointed out by Schiffer (1972: 13), there must be some link between what $C$ means and what he uses to mean it. For me, this link may be of two kinds: natural or conventional. Notice, however, that the limit between both types may be fuzzy: for instance, linguistic meaning, which is often regarded as - and certainly is, at the very beginning - conventional, may also be considered as natural once the convention is so strongly established that everyone has forgotten it. ${ }^{11}$ On the other hand, one can always create a new code and use it to communicate, grounding one's meaning on this convention. Anyway, it cannot be maintained that any stimulus is able to convey any message. I may communicate to you that I have broken my finger by showing you my splint with the required intention (relying, then, on natural meaning), or by telling you "I have broken my finger" (relying, then, on linguistic meaning), but it would be difficult to get the same result by shaking my head, for instance. We have just seen that, for Grice (and sometimes for $S \& W$ ), there is no communication in the first case. However, even in verbal interaction, it is not always easy to determine whether a given stimulus provides evidence for some information or evidence of C's intention to convey it. Consequently, even if there exists, in verbal interaction, a presumption that something is communicated, we still have to determine what really is communicated. For instance, one may wonder on which criteria $S \& W$ ground their claim that showing a tube of aspirin is indirect evidence of headache and speaking with a hoarse voice direct evidence of a sore throat. I would prefer to consider (in)directness as a gradable property, and accept any of these cases as an example of communication - all the more so since $\mathrm{S} \& \mathrm{~W}$, finally, seem to share this view.

Livet (1994: 46) argues that, in the case of Herod showing St John the Baptist's head to Salome, Salome does not need to attribute a communicative intention to Herod in order to understand that St John is dead, since his head on a trail is natural evidence of his death. That is right, but she can still infer that Herod wants to communicate, because nothing 
prevents him from doing so, neither her from interpreting the situation as such. According to Livet, however, to force $\mathrm{A}$ to attribute to $\mathrm{C}$ a communicative intention, $\mathrm{C}$ must use nonnatural evidence for the information he wishes to convey. It seems to me that, even so, the act of showing the head may be sufficient to assume that Herod has a communicative intention, though other interpretations remain possible, depending on the analysis one makes of the situation. On this issue, I follow Schiffer (1972: 20-21) and Récanati (1986), who both consider that when Herod shows St John's head to Salome in order to inform her of his death, he can undoubtedly communicate. Moreover, Schiffer (1972: 56-57) sees no difference between showing a bandaged leg in reaction of an invitation to play, squash (which would be indirect evidence for a refusal) and showing it in order to answer to "I heard that your leg was bandaged. Is that true?" (which would be direct evidence). Neither do I.

To come back to S\&W, I must add that, for me, ostension effectively seems to involve some use of indirect evidence, since it makes manifest some intention to make something manifest. But nothing ensures that it does not also give direct evidence for this information. In such a perspective, Herod's behaviour is a good example of ostension. S\&W themselves write that "sometimes all the evidence displayed in an act of ostension bears directly on the agent's intentions" (1995: 52), which entails that the same does not hold for some other cases. In conclusion, I think it unnecessary to impose a restriction on the kind of evidence $\mathrm{C}$ should use in order to communicate. It is a natural consequence of the intentional definition of communication that $\mathrm{C}$ shows some evidence of his intentions. As soon as there is some evidence of a communicative intention, one may be considered as communicating, whether or not one gives also direct evidence for the conveyed information.

\section{Unintentional communication}

In all (post-)Gricean approaches, communication is a matter of intentions, even if every singular definition imposes restrictions of its own on the form or content of intentions. In the following, I will determine which intentions a communicator must have, and which ones he must make manifest; this will allow me to better capture the differences between both requirements.

Since I view communication as a particular kind of action, I hold that it is always intentional and involves particular kinds of intentions. Although they agree that communication is basically intentional, $\mathrm{S} \& \mathrm{~W}$ claim that, according to their definition, it may sometimes turn out to be unintentional. As the example they give in their book (1995: 63-64) may seem unconvincing, I will discuss here a slightly different case (Sperber, personal communication). Imagine that a vase has broken and $C$ wants $A$ to know about it without having $\mathrm{A}$ know about his informative intention. Thus $\mathrm{C}$ has an informative intention but he has no intention to communicate; that is, $\mathrm{C}$ has no intention to produce a stimulus that makes mutually manifest to $A$ and $C$ that $C$ has this informative intention. In order to inform $\mathrm{A}, \mathrm{C}$ puts the pieces of the vase in a place where $\mathrm{A}$ cannot fail to notice them. 
Unfortunately, $A$ sees what $C$ is doing, and $C$ also sees (in a mirror, for instance) that $A$ is looking at him and that $A$ sees that $C$ is aware of this. In consequence, $C$ 's informative intention becomes mutually manifest to $\mathrm{A}$ and $\mathrm{C}$, so that unintentional communication takes place.

Up to now, I have assumed that $S \& W$ consider communication as a kind of behaviour (ostension is defined this way), and so as a kind of action. I have also supposed that they define communication by the conjunction of two intentions that $\mathrm{C}$ should have in producing his stimulus (see 1995: 58 \& 61). However, in this last example, $\mathrm{C}$ obviously has no communicative intention; on the contrary, he has the opposite intention not to make his informative intention manifest to $\mathrm{A}$. What happens here is that his attempt fails: while producing his stimulus, he involuntarily makes manifest his informative intention. In my view, this does not entail that $C$ communicates, even if the whole story proves compatible with one of S\&W's definition (see 1995: 63; quoted above), which contradicts another one (1995: 61; also quoted above). The former definition does not characterize the production of the stimulus as precisely as the latter one: indeed, this production may be intentional and still not involve a communicative intention. In such a case, the intention at work does not characterize any particular kind of action; what we have is just an action whose particular consequences may even be independent of C's intentions. S\&W's claim would be justified if they reduced communication to a simple result, analyzing thus the whole situation instead of people's actions and intentions. Such a view would confuse the communicative process or at least the communicative result of some action - with the act of communication itself. But if we focus on this very act, we should not require any intervention of A's in order to assess which cases are instances of communication. It seems to me that, in the example under discussion, $\mathrm{C}$ does not communicate and that, furthermore, $\mathrm{A}$ will not consider $\mathrm{C}$ as a communicating agent: by noticing, for instance, that $C$ was annoyed when seeing $A, A$ will probably understand that $C$ did not want to make his intention manifest. So $A$ will attribute to $\mathrm{C}$ an intention to dissimulate his informative intention rather than an intention to make it mutually manifest (see also Livet 1994: 57). And even though A interpreted C's action as an act of communication, this alone would not entail that $\mathrm{C}$ was really communicating. In my opinion, no interpretation can, by itself, create any reality, except perhaps in a normative framework, where $\mathrm{C}$ would be held responsible of what his behaviour manifests. But $S \& W$ clearly have no intention to introduce such a normative flavour in their model. To sum up, it seems advisable to stick to the idea that communication is intentional, which means that $\mathrm{C}$ communicates if he produces some stimulus with some communicative intention linked to this production.

\section{Having, manifesting or recognizing intentions}

As shown in section 2, the Gricean definition of non-natural meaning mentions the production of a stimulus with a set of specific intentions, which $\mathrm{C}$ is supposed to have. This set includes, among others, an intention to have some intention recognized. On the other 
hand, S\&W often talk of making intentions manifest. What are the differences and the relationships between manifesting, having, and recognizing an intention ?

Obviously, you can have an intention which is not manifest to anybody else, so that it remains completely private. But communication involves public intentions, i.e. intentions that are made manifest to other people. They can be manifest either because someone has made them manifest intentionally, or simply because of the situation. Conversely, one can make an intention manifest without having it. But if $\mathrm{C}$ makes one of his intentions mutually manifest to $\mathrm{A}$ and $\mathrm{C}$, he must have this intention. If he did not have the intention he pretended to have, he could not make this intention mutually manifest to A and to himself, since he would know that he hasn't this intention, which then could not be manifest to himself. Indeed, for any individual, manifestness entails truth or the probability of truth.

Let me illustrate these distinctions with the help of an example. By announcing his forthcoming departure, $\mathrm{C}$ may intentionally make manifest an intention to leave, which he may have or not, and, by doing so, he may provide evidence for an intention of his not to come back ever again, without wanting this intention to be manifest. In communication, what matters is making intentions manifest, and even making them manifest intentionally, since communication is a kind of action. In my example, $\mathrm{C}$ will be considered as communicating his departure, but not as communicating his desire to stay away for ever. In my view, whether $\mathrm{C}$ really has or not the informative intention he makes manifest, has no incidence on communication as long as his insincerity remains hidden. Practically, however, communicators are considered as having the intentions they make manifest, otherwise communication would become impossible. In S\&W's intentional framework, the situation is totally different: $\mathrm{C}$ must have the informative intention in order to make it mutually manifest, and he must have the communicative intention, if we want to maintain the intentionality of communication. In consequence, lying, for instance, is no communication at all.

An intention to make something manifest is weaker than an intention to make it recognized, since manifest only means "recognizable". For me, in communicating, $\mathrm{C}$ has the intention that his intentions shall be recognized by $\mathrm{A}$; but the only thing he can aim at is making his intentions manifest to $\mathrm{A}$ (or, at least, as manifest as possible), with the hope that A will effectively form the corresponding representations. For example, when you order someone to close the door, you intend him to recognize your intention, you do not just intend him to be able to recognize it. Unfortunately, in practice, you can only make your intention manifest to him, without ensuring its recognition. In fact, we may consider that $\mathrm{C}$ has managed to communicate if he has made his intentions manifest to $\mathrm{A}$; but the content of his intentions involves A's recognition of them, so that C's act of communication is satisfied only when A recognizes those intentions of C's. This is an intuitive analysis of mine, which posits intentions that slightly differ from Grice's or S\&W's ones, even though they resemble them.

My intuitive requirement as a whole also differs from $S \& W$ 's one. According to them, communication is "successful" as soon as the communicative intention is fulfilled, i.e. as soon as the informative intention is mutually manifest to $A$ and $C$. In this situation, the 
content of the informative intention, as well as a set of assumptions $\{I\}$, must be manifest to A too; consequently, the informative intention is also fulfilled. Yet S\&W argue that the informative intention is not necessarily fulfilled, and that such a result depends on $A$, who can always refrain from accepting $\{I\}$ as a set of true assumptions, thereby provoking the failure of the act of communication. Since this thesis could easily come against the wellknown objection of "the perlocutionary effect", S\&W describe the content of the informative intention as a modification of A's cognitive environment and not as some response of A's. But, if we are to believe our intuition, the acceptance of assumptions as true has nothing to do with pure communication; it rather concerns some speech act (e.g. an assertion or an attempt to convince). For instance, if someone understands your utterance without believing you, you will consider that your communication is "successful" though your illocutionary or perlocutionary intention is not fulfilled.

The fact that manifestness is a very weak requirement will also create problems when we turn to account for communication in an interactional perspective. Indeed, for an informative intention to be manifest to A, A does not need to recognize it, nor does he need to build up an effective representation of the conveyed set of assumptions $\{\mathbf{I}\}$. One may wonder how, on such modest premises, the act of communication could initiate a process of communication.

When S\&W talk of making intentions manifest, they seldom specify whether this manifestation is intentional or not. Such a neglect explains, perhaps, their claim that communication may be unintentional and their account of the examples which substantiate this disputable thesis. In my opinion, if one wishes to adopt S\&W's framework, one has to stipulate that, in order to communicate, $\mathrm{C}$ must intentionally produce a stimulus which makes an informative intention mutually manifest, and his intention in producing the stimulus must be a communicative one.

\section{Ostension and communication}

Let us turn, now, to the definition of communication by means of ostension, and see whether we can get some other clue there. Ostension is a kind of behaviour that makes manifest an intention to make something manifest. Since S\&W do not indicate clearly whether such a behaviour must be intentional or not, we should distinguish between different possible layers of manifestness and intentionality: (1) $\mathrm{C}$ makes $\mathrm{x}$ manifest to $\mathrm{A}$, intentionally or not; (2) $\mathrm{C}$ (necessarily intentionally) makes $\mathrm{x}$ manifest to $\mathrm{A}$, and $\mathrm{C}$, intentionally or not, makes manifest to $\mathrm{A}$ an intention to make $\mathrm{x}$ manifest to $\mathrm{A}$; and so on ad infinitum.

I think that $\mathrm{S} \& W$ would say, about case (1), that $\mathrm{C}$ informs $\mathrm{A}$ of $\mathrm{x}$ if $\mathrm{C}$ has the corresponding intention. If $\mathrm{C}$ has no such intention, we have a typical instance of natural meaning. This result agrees with our intuitions. Let us take our example of the broken vase again. If A simply happens to see the pieces of the vase, then the situation means - naturally - that the vase is broken. As long as A does not suppose that $C$ has arranged the pieces in 
order to make it manifest to him that the vase is broken, he won't attribute any intention to $\mathrm{C}$ nor consider $\mathrm{C}$ as informing him. But if he assumes that $\mathrm{C}$ has done so, he will consider that $\mathrm{C}$ has informed him. That does not mean that $\mathrm{C}$ has communicated, since $\mathrm{A}$ may suppose that $C$ had no intention to make his informative intention manifest.

About case (2), S\&W would speak of ostension and thus of communication. That means that $\mathrm{C}$ just informs $\mathrm{A}$ of an informative intention. But if communication is only information about an intention, that is a special case of information, why should one posit a communicative intention? Here we clearly see that S\&W's two definitions of communication do not match. When dealing with ostension, S\&W do not mention mutual manifestness, while mutual manifestness is essential to their intentional definition of communication and the communicative intention. Assume, for the sake of the argument, that communication just amounts to producing a stimulus with a communicative intention, thus making an informative intention mutually manifest. This requirement is stronger than the condition for ostension, which only consists in making manifest to A (and not mutually manifest to $A$ and $C$ !) an informative intention. S\&W themselves emphasize that communication has social implications that information does not have, and that such phenomena cannot be accounted for without some reference to mutual manifestness.

Even if "successful communication" requires the mutual manifestness of the informative intention, this does not entail, in S\&W's view, that the communicative intention should be manifest. Contrary to what happened in Grice's model, the overtness of communication does not result in an infinitely regressive definition of the communicative intention. However, we will see in the next section that there is infinite regress in the notion of mutual manifestness, which should ground the difference between communication and ostension, or the difference between communication and information.

In the following, I will abandon the definition by means of ostension. I will consider that $S \& W$ 's notion of communication involves an informative and a communicative intention as defined above.

\section{Infinite regress, reflexivity and mutual manifestness}

As soon as one wishes to ensure that communication is overt, i.e. that all the intentions of C's involved in communication are overt, one cannot escape from assuming either an infinite regress of intentions or a reflexive intention which both are rather unplausible from a psychological viewpoint. In "Meaning" (see section" 1), Grice considered that the communicative intention consists in three sub-intentions, viz. (1) that A produces a response $r$, (2) that $A$ recognizes that $C$ has intention (1), and (3) that A fulfils (1) because of his satisfaction of (2). This formulation does not lead to any form of infinite regress but does not warrant overtness either: $C$ can keep his intentions (2) and (3) secret; in such a case, say Schiffer and Strawson, we do not intuitively believe that $\mathrm{C}$ communicates. While accepting the criticism, Grice pointed out that if one adds a fourth intention, requiring that $\mathrm{A}$ recognizes (2) and (3), one is faced to a similar objection, since nothing ensures the 
overtness of this fourth intention. Consequently, this way out would result in an infinite regress of intentions, which he found psychologically unplausible. In fact, the examples which could illustrate the (non-)overtness of the fourth, fifth,... intention, though theoretically sound, largely exceed the cognitive power of ordinary speakers. Consequently, Grice claimed that overtness is an unreachable idealization. In practice, people rely on default approximations: when they do not see any element that would contradict optimal conditions, they conclude that these are approximately fulfilled. In the same perspective, Récanati's definition of the communicative intention rests on the concept of default reflexivity: "S's intention is default reflexive if and only if $S$ has no intention inconsistent with any of the (infinite number of) intentions that his intention would entail if it were genuinely reflexive" (1986: 234); so the communicative intention is "an open (default reflexive) intention (a) that $\mathrm{u}$ give $\mathrm{A}$ reason to believe that $\mathrm{PC}^{12}$, and (b) that $\mathrm{A}$ recognize (a), and recognize it as open" (1986: 238).

Schiffer (1972: 30-42) attempted to solve the problem of the infinite regress of the communicative intentions by using the notion of mutual knowledge. Basically, when $\mathrm{C}$ communicates, $\mathrm{C}$ must intend to realize a state of affairs $\mathrm{E}$ which is mutually known by $\mathrm{A}$ and $\mathrm{C}$ and which provides evidence both of his intention to realize $\mathrm{E}$ and of his informative intention. Consequently, these intentions have to be mutually known for communication to succeed. Unfortunately, as shown by $\mathrm{S} \& \mathrm{~W}$, the very concept of mutual knowledge involves infinite regress and is thus psychologically unplausible. For $S \& W$, nobody can aim at mutual knowledge or stick to it when communicating. Grice also accepted the psychological implausibility of mutual knowledge; but he immediately proposed to consider it as an idealization that cannot be reached in our world, so that humans, in interpretation, would rely on default approximations of mutual knowledge.

To S\&W, Grice's solution, which consists in considering every form of infinite regress as an idealization, does not seem more plausible than Schiffer's approach. In order to escape from infinite regress, they introduce a notion that, according to them, does not create the same psychological problems: mutual manifestness. Contrary to what happens with mutual knowledge, mutual manifestness does not require that the individuals effectively construct the representation of every assumption up to a given degree of reflexivity. Indeed, an assumption may be manifest without being represented. Consequently, it becomes psychologically plausible that some assumptions are mutually manifest. Notice, however, that there cannot be any definite evidence of the fact that some assumption is manifest to someone: $S \& W$ themselves sometimes claim that the fulfilment of the informative intention remains in A's hands. Consequently, mutual manifestness involves the same bets as does mutual knowledge: $\mathrm{C}$ grounds his utterance production on what he thinks is manifest to $\mathrm{A} .{ }^{13}$

Anyway, S\&W rely on the notion of mutual manifestness to ensure the overtness of communication. This is, in part, the reason why I finally kept the intentional definition of communication rather than the definition by means of ostension, which does not involve any mention of mutual manifestness. Let me repeat this definition here: $\mathrm{C}$ communicates iff he produces a stimulus intending thereby to make mutually manifest to $A$ and to $C$ his intention to make some set of assumptions $\{$ I $\}$ manifest (or more manifest) to A. Now, I would like 
to discuss the following questions: Does mutual manifestness involve some form of infinite regress? Can mutual manifestness ensure the overtness of communication? What consequences does mutual manifestness have regarding our intuitive conception of communication?

Let us first prove, after Dominicy (1991), that S\&W's definition of the communicative intention entails a peculiar form of infinite regress. If communication is "successful", the informative intention must be mutually manifest to $\mathrm{A}$ and $\mathrm{C}$. So, it must be manifest to $\mathrm{A}$ and $C$ (i) that $C$ has the informative intention, (ii) that it is manifest to $A$ and $C$ that $C$ has the informative intention, (iii) that it is manifest to $A$ and $C$ that it is manifest to $A$ and $C$ that $\mathrm{C}$ has the informative intention, and so on ad infinitum. The problem is that this infinitely regressive assumption is the content of the communicative intention. We have to assume, with Dominicy (1991), that the communicative intention represents a desirable state of affairs in which the informative intention is mutually manifest to $\mathrm{A}$ and $\mathrm{C}$. It follows that the communicative intention should also represent the logical structure of the set of those assumptions that are mutually manifest to $\mathrm{A}$ and $\mathrm{C}$. But, in such a perspective, one cannot see how this intention could ever be fulfilled by an action. And if one transforms the degree of manifestness of each assumption into a degree of intentional force, one just reintroduces an infinite regress of intentions. Thus, $\mathrm{S} \& W$ 's definition comes against the same objections as Grice's one, even though the intentions involved have a different content. Grice's infinite regress bears on the recognition of intentions while S\&W's one bears on the realization of the communicative intention.

When communication is "successful", Grice's definition of communication does not entail any mutual manifestness to $\mathrm{A}$ and $\mathrm{C}$ that $\mathrm{C}$ has an informative intention, but rather the manifestness to $A$ of an infinite number of intentions of C's. In S\&W's model, there will be no infinite number of intentions manifest to $\mathrm{A}$, but one intention of $\mathrm{C}$ 's will be mutually manifest to $A$ and $C$. It is not obvious to me that $S \& W$ 's constraint really ensures the overtness of the communicative intention. Suppose $C$ has a deceitful intention, what prevents him from being considered as "communicating" in S\&W's sense? Nothing, in my opinion, since mutual manifestness does not necessarily involve any intentionality. Remember, for instance, Sperber's example of "unintentional communication": you can transform it a little bit in order to get a case of "communication" in which C intends to deceive $A$; you only need to assume that $C$ has a communicative intention but intends $A$ to believe that he has none. If $\mathrm{C}$ behaves the way he does in Sperber's original example, the whole story looks like a perfectly plausible example of "communication" in S\&W's sense. Still, nobody would spontaneously say that $\mathrm{C}$ communicates.

On the other hand, such a conception also entails that $\mathrm{C}$ has the informative intention he makes mutually manifest. One may wonder, then, how "successful lies" could be accounted for in Relevance Theory. Indeed, according to Grice's or Récanati's definitions, and ordinary intuition, a liar will be considered as communicating in a normal way as long as one does not convict him of lying. In other words, $\mathrm{C}$ is assumed to communicate as long as $\mathrm{A}$ does not detect any intention that would conflict with $\mathrm{C}$ 's putatively communicative 
intention. In S\&W's model, such a situation cannot happen; yet we all feel that it actually can.

Finally, S\&W's definition entails that $C$ has the intention that A's understanding of C's communicative act is manifest to $\mathrm{C}$ - which is not required in Grice's definition. I personally think that $\mathrm{C}$ may be considered as communicating even though it is not manifest to him that A has correctly interpreted his act. The success of communication does not depend on A nor on C's perception of A's reaction. It would be useless for C to aim at being able to reconstruct A's understanding; in some cases, it will even be impossible. Otherwise novelists, journalists, etc. would never communicate, since they certainly do not try to access to their readers' understanding and apparently do not intend to reconstruct it. In their rejoinder to this objection (1995: 63), S\&W argue that when journalists, professors or political leaders communicate, their informative intention is presumed to be mutually manifest; so, as soon as they make an informative intention manifest, it becomes mutually manifest. In my view, this conjecture is either trivial or highly unplausible. If the mutual manifestness of an informative intention does not involve the mutual manifestness of the corresponding set of assumptions $\{\mathbb{I}\}$, then S\&W's claim simply predicts that it will be mutually manifest to $C$ and $A$ that $C$ has an informative intention, whatever it may turn out to be. If, on the other hand, the mutual manifestness of an informative intention does involve the mutual manifestness of the corresponding set of assumptions $\{I\}$, then S\&W's claim entails that $C$ must have a true knowledge of A's understanding; which is impossible. Of course, everybody wants to be understood but I do not believe that everybody wants to know for sure that which process of understanding has taken place. Moreover, such a dimension would rather concern the analysis of the communicative process; and that is another story.

\section{Conclusion}

As the reader may guess after such a lengthy discussion, I am not fully satisfied with S\&W's definition(s) of communication. In fact, S\&W do not provide us with a sharp and consistent conception which they would maintain in their whole book. There is a lot of fuzziness or contradiction in and between the different definitions that they propose. Are we supposed to opt for one or another version? I tried to do so. Unfortunately, no definition really captures what one should mean by the term "act of communication". The intentional perspective adopted by $S \& W$ seems both traditional and legitimate, but their characterization of the informative and communicative intentions rises several objections. S\&W simply fail to describe what we intuitively consider as an act of communication. Instead of solving the problem of the infinite regress of intentions, they just shift it to another level, so creating new difficulties.

The notion of manifestness, as well as S\&W's view of communication based on inference and on the modification of cognitive environments, may be useful when we come to analyze what really happens in communication, focusing then on the possession, 
representation and recognition of intentions. Yet, in this perspective, I would rather rely on some modified version of Récanati's definition of communication (1986: 238). The attractiveness of Recanati's approach is due to his acceptance of direct evidence and to his fine-grained treatment of manifestness, recognition and default reflexivity; this seems to me the only way to ensure overtness without indulging into psychological implausibility. I think that such a definition could be integrated in the framework of Relevance Theory, and consequently substitute for S\&W's problematic formulations. This issue should be the topic of another paper.

\section{Notes}

* Research supported by Fonds National de la Recherche Scientifique (Belgium).

1. I thank Marc Dominicy for his precious advice, as well as for his patient corrections of earlier drafts of this paper.

2. From now on $\mathrm{S} \& \mathrm{~W}$.

3. This way of conceiving action has been criticized by many authors. But its inadequacy has no direct bearing on my argumentation.

4. Here I apply to the act of communication the Searlean notions of success and satisfaction, which are originally defined for speech acts (see e.g. Searle \& Vanderveken 1985).

5. When commenting on S\&W's rejection of speech act theories, Blakemore (1991: 198) argues that those theories are "concerned with language as a vehicle for action rather than as a vehicle for thought".

6. For a critical discussion, see e.g. Bird (1994).

7. See e.g. Searle (1969), Récanati (1987).

8. See Récanati (1986), Schiffer (1972).

9. See Strawson (1971), Récanati (1986 \&1987). For an alternative solution, see also Schiffer (1972), who relies on the notion of mutual knowledge.

10. Contrary to my own usage (see above), S\&W do not make any distinction between the success and the satisfaction of an act of communication. While, in S\&W's sense, "success" seems to refer to the performance of an act of communication, their requirement rather bears on its satisfaction.

11. This accounts for the fact that a sentence pronounced by a delirious person or produced by a computer can convey some well-determined information in the absence of any (informative or communicative) intention.

12. The symbol " $\mathrm{u}$ " refers to the utterance and "PC" means that the prototypicality conditions associated with the speech act obtain.

13. Livet (1994: 57-60) too notes that the notion of a mutual cognitive environment creates the same problems as mutual knowledge, since both imply multiple extensions in some variety of non-monotonic logics.

\section{Works cited}

Allwood, Jens S. Linguistic Communication as Action and Cooperation. Doctoral dissertation. 
University of Göteborg (Department of Linguistics): Gothenburg Monographs in Linguistics 2, 1976.

Bird, Graham. "Relevance Theory and Speech Acts." Foundations of Speech Act Theory : Philosophical and Linguistic Perspectives. Ed. S.L. Tsohatzidis. London/New York: Routledge, 1994. 292-311.

Blakemore, Diane. "Performatives and Parentheticals." Proceedings of the Aristotelian Society 91 (1991): 197-213.

Dominicy, Marc. "Compte rendu: Dan SPERBER et Deirdre WILSON, La Pertinence. Communication et cognition, traduit de l'anglais par Abel Gerschenfeld et Dan Sperber, Paris, Les Editions de Minuit, 1989." Le Français Moderne 59, 1 (1991): 85-91.

Grice, H. Paul. Studies in the Way of Words. Cambridge (Mass.): Harvard University Press, 1989

Livet, Pierre. Ia communauté virtuelle: Action et communication. Combas: Editions de l'Eclat, 1994.

Meijers, Anthonie. Speech Acts. Communication and Collecive Intentionality. Proefschrift, doctoraat thesis. Leiden: Rijksuniversiteit te Leiden, 1994.

Récanati, François. "On defining communicative intentions." Mind and Language 1/3 (1986): $213-42$.

Meaning and Force. Cambridge: Cambridge University Press, 1987

Schiffer, Stephen. Meaning. Oxford: Clarendon Press, 1972.

Searle, John R. Speech Acts. Cambridge: Cambridge University Press, 1969 (1984).

Searle, John R, Daniel Vanderveken. Foundations of Illocutionary Logic. Cambridge: Cambridge University Press, 1985.

Sperber, Dan, Deirdre Wilson, Relevance: Communication and Cognition. Oxford: Blackwell, 1995 (1 ${ }^{\text {st }}$ edition, 1986).

Strawson, P.F. Logico-Linguistic Papers, London: Methuen \& Co Ldt, 1971.

Wilson, Deirdre, Dan Sperber. "Remarques sur l'interprétation des énoncés selon Paul Grice", Communication 30 (1979): 80-93. 